\title{
Experiences of Spirituality and Spiritual Values in the Context of Nursing - An Integrative Review
}

\author{
Gudrun Rudolfsson ${ }^{*}, 1$, Ingela Berggren ${ }^{1}$ and António Barbosa da Silva ${ }^{2}$ \\ ${ }^{I}$ Department of Nursing, Health and Culture, University West, SE-461 86 Trollhättan, Sweden \\ ${ }^{2}$ Ansgar College and Theological Seminary, Kristiansand, Norway
}

\begin{abstract}
Spirituality is often mistakenly equated with religion but is in fact a far broader concept. The aim of this integrative review was to describe experiences of the positive impact of spirituality and spiritual values in the context of nursing. The analysis was guided by Whittemore and Knafl's integrative review method. The findings revealed seven themes: 'Being part of a greater wholeness', 'Togetherness - value based relationships', 'Developing inner strength', 'Ministering to patients', 'Maintaining one's sense of humanity', 'Viewing life as a gift evokes a desire to 'give back', and 'Achieving closure - life goes on'. It is difficult to draw definite conclusions, as spirituality involves many perspectives on various levels of awareness. However, spirituality was considered more inclusive, fluid and personal. Furthermore, it emerged that spirituality and spiritual values in the context of nursing are closely intertwined with the concept of caring.
\end{abstract}

Keywords: Humanity, integrative review, inner strength, spirituality, togetherness, wholeness.

\section{INTRODUCTION}

The holistic view of the human being as a unity of body, soul and spirit [1] requires that these terms are defined. According to Barbosa da Silva [2], one way of defining the body refers to the organism, the physical dimension of the human being, which has the following quantitative characteristics: "is visible, has volume, weight and is extended in time and space, manipulability and quantitatively measurable. As a biological organism, man is a quantitative whole that interacts with nature, especially the ecological environment". By soul we mean "the part of human life, beyond the purely organic, is not manipulable and not quantitatively measurable, and that causes different reactions, social relations, emotions, perceptions, behaviours, actions, differing needs and ways to satisfy them". Frankl [1] defines the soul as "the human person in its entirety" (pp. 1827).

Spiritual needs and spirituality are often mistakenly equated with religion. Greenstreet [3] states that within the nursing context, spiritual needs and spirituality should be seen as a broad concept encompassing religion but not equated with it. However, the fact is that no one can define spirituality exactly [4]. This is not to say that spirituality as a human phenomenon in the nursing context does not exist. Kevern [5] suggests that spirituality concerns questions of values and meanings that are fundamental in the search for

*Address correspondence to this author at the Department of Nursing, Health and Culture, University West, SE-461 86 Trollhättan, Sweden;

Tel: + 46 (0) 5202239 79, 46 (0) 52073245 ;

E-mails: gudrun.rudolfsson@hv.se, gudrun.rudolfsson@comhem.se meaning in life [3]. Spirituality is always viewed as morally or aesthetically valuable [4]. As Timmins and McSherry [6] stress, spirituality is embedded within the core values of everyday nursing practice and not something that is added. Furthermore, one cannot be a nurse without encountering the human spirit at some point and knowing something about spirituality. In a situation of illness, people are likely to think about spiritual values in an attempt to alleviate suffering [7].

Swinton and Pattison [7] criticized the breadth of spirituality in the nursing literature for being overly inclusive and commented that everything that encompasses spiritual care should simply be called good person-centred care. Furthermore, these authors stress that the search for the essence of spirituality in nursing is pointless as the meaning of spirituality evolves from certain circumstances and can therefore change. A number of reports [6] that are critical of nurses for failing to provide care based on compassion, dignity and moral integrity may be explained by the fact that caring has become morally and aesthetically disconnected from the spiritual dimension as a result of too much focus on medical, physiological and technical issues.

In an overview of nursing research on spiritual care, Ross [8] identified elements of spirituality including faith, meaning, love, belonging, forgiveness and connectedness. Dalby [9] investigated the meaning of spirituality in relation to ageing and identified the following themes: integrity, changing relationships with others and with a transcendent being and coming to terms with death.

In a conceptual analysis by Tanyi [10], spirituality was viewed as broader than religion and involving human beings' search for meaning in life. The definition that emerged was: "spirituality is a personal search for meaning and purpose in 
life, which may or may not be related to religion. It entails connection to religious beliefs, values and practices that give meaning to life, thereby inspiring and motivating individuals to achieve their optimal being" [p. 506]. Here spirituality seems to be primarily considered in an existential sense.

Stoll [11] described spirituality as: "Who I am — unique, and personally connected to God. That relationship with God is expressed through my body, my thinking, my feelings, my judgments, and my creativity. My spirituality motivates me to choose meaningful relationships and pursuits. Through my spirituality I give and receive love; I respond to and appreciate God, other people, a sunset, a symphony, and spring. I am driven forward, sometimes because of pain, sometimes in spite of pain. Spirituality allows me to reflect on myself. I am a person because of my spirituality motivated and enabled to value, to worship, and to communicate with the holy, the transcendent" [11 p. 9]. In accordance with these definitions, all humans are spiritual beings and need not be religious to be spiritual. Spirituality is individual, encompassing relational components and one's search for the meaning and purpose of life.

Despite a large number of reviews on spirituality, for example, in the context of palliative care [12], nursing management $[13,14]$, recovery from surgery [15] and spiritual needs [16], there is a lack of clarity in research concerning differences in the views of spirituality and spiritual values in the context of nursing, which is therefore the subject of this study.

\section{AIM}

The aim of this integrative review was to describe experiences of the positive impact of spirituality and spiritual values in the context of nursing

\section{METHOD}

Whittemore and Knafl's [17] integrative review method guided the analysis as we wanted to include various primary studies with different perspectives on the concepts of spirituality and spiritual values. The integrative review method consists of data reduction, data display, data comparison, interpretation and conclusion drawing $[17,18]$. Integrative reviews can also combine both quantitative and qualitative data from the theoretical as well as empirical literature. This broad sampling frame has the potential to result in a comprehensive depiction of complex concepts, such as spirituality and spiritual values [17].

In the light of the above and the aim of this study, we distinguish between the terms 'spirituality' and 'spiritual values' to systematize the types of text analyzed as follows. The term 'spiritual' occurs in the literature with different meanings. In accordance with Barbosa da Silva [2 p. 114], we will briefly clarify three of its most common meanings.

Firstly, the word 'spiritual' is used as a synonym for 'cultural', for example, in political contexts when it is stated that "we must preserve our spiritual heritage" the focus is on both spirit and culture [2]. According to Dilthey, human sciences (Ger. Geisteswissenschaften) study the human being as cultural, spiritual and social [2].
Secondly, the word 'spiritual' is a synonym for 'existential' when discussing 'spiritual issues' in the sense of existential questions [3,10]. Existentialist philosophers such as Kierkegaard [19], Buber [20] and Frankl [1] consider the experience of life, suffering, guilt, fear, freedom, responsibility, moral conscience and despair as spiritual. Buber [20] argued that the spirit is not in the self, but expresses itself in an authentic communication between two or more human subjects, me and you. The fact that a human experience is spiritual in an existential sense implies that it is characteristic of the human existence per se. Thus, Barbosa da Silva [2] concluded that what is existential (spiritual) is also universal in the sense that it is considered to belong to all people at all times and in all places.

Thirdly, the term 'spiritual' is used as a synonym for 'religious'. Examples of spiritual and religious experiences include guilt, the need for reconciliation with God, the hope of eternal life and the meaning of suffering as an expression of God's plan for the human being. As this study demonstrates, these three meanings of the word 'spiritual' may be relevant in a healthcare situation or to the extent that patients can express their spiritual needs, the satisfaction of which is relevant to their treatment [2]. Thus we will distinguish between cultural, existential and religious spirituality.

\section{Study Selection Criteria}

Studies considered for inclusion were qualitative research papers, primary sources dealing with spirituality in the nursing context and empirical or theoretical literature published in the English language. The exclusion criteria were quantitative articles, review articles and papers concerning the education of nursing students.

\section{Search Method}

The initial search in the CINAHL electronic database in December 2012 using the keyword spirit* yielded a total of 15,275 papers. To reduce the number of hits and focus on the concept of spirit*, this keyword was further combined with 'patient*', 'empirical', 'wellbeing', 'spiritual support', 'holistic spirituality', 'caring', 'nurs*', 'philosophy', 'old age' and 'spiritual care'. A second search in the CINAHL electronic database following the same procedure was carried out in January 2013. In addition, the Journals of Nursing Philosophy (4 hits) and Nursing Ethics (5 hits) from 2008 to 2012 were searched more systematically while secondary searches were also conducted on the homepages of various other randomly selected Nursing Journals. Finally, a search was performed in February and March 2013 in the Scopus database using the same keywords and procedure. Additionally, during the analysis process, an ongoing search was performed in the Scopus database to obtain updates, from which one additional article emerged. There were no restrictions in terms of year of publication in any of the search processes.

According to Whittemore and Knafl [17], there is no gold standard for evaluating and interpreting quality in research reviews. Therefore, data relevance refers to the extent to which the studies met the aim of this integrative review and 
for this reason; no studies were excluded due to poor methodological quality.

\section{Search Outcome}

A total of 97 studies were identified. Abstracts or full articles were examined in several steps by two of the authors. This procedure ended with the selection of 26 articles published between 1999 and 2013 that met the inclusion criteria. The findings of each study were scrutinized to identify experiences of spirituality and spiritual values in the context of nursing. In this process a further 11 articles were excluded when it became clear that spirituality was not in focus. As a result, the research material comprised 15 articles, including a total of 730 patients, aged 27-79 years, 52 staff members and former caregivers, aged 23-70 years, and 9 family members. Of these participants, 262 were female and 172 male. Two articles were European (one from Sweden and one from England), while nine were published in the USA, two in Australia and two in Iran. Data collection methods used were in-depth, focus group, semi-structured and telephone interviews, interview-like interactions and narratives (Table 1). All studies used some kind of descriptive design. Three had a phenomenological, one a phenomenographical, one a hermeneutic phenomenological and one a phenomenological hermeneutic approach in addition to which one employed qualitative content analysis, two grounded theory analysis and two articles were theoretical.

\section{Analysis}

Data reduction involved categorizing the data from each article in a matrix based on the study type. In data display, extracts from each article were placed in the matrix to illustrate patterns and facilitate comparison. Data comparison involved making comparisons across the studies and examining the data to identify differences and similarities between themes. During the interpretation process the patterns and relationships identified were described and raised to a higher level of abstraction. Conclusions were drawn that captured the breadth, depth and relevance of the data [17].

\section{RESULTS}

The integrative review of experiences of spirituality and spiritual values in the context of nursing produced seven themes: 'Being part of a greater wholeness', 'Togetherness value based relationships', 'Developing inner strength', 'Ministering to patients', 'Maintaining one's sense of humanity', 'Viewing life as a gift evokes a desire to 'give back', and 'Achieving closure - life goes on'.

\section{Being Part of a Greater Wholeness}

Spirituality was described as the integration of body, mind and spirit in to a harmonious whole [21]. The comprehensive perspective emerged as being part of a greater picture [21] and an understanding of something greater than oneself, or awe when, for example, walking in nature [22]. It was also expressed as a search for the sacred through subjective feelings, thoughts and behaviours [22]. According to Yuen [22] and Tanyi et al. [23], the essence of spirituality is general well-being and meaning in life, creating wholeness, a sense of something larger than oneself and relating it to individual situations. Hence spirituality has a positive effect on patients' health and promotes recovery [24] thus leading to the ability to view life from different perspectives [21]. In moments of uncertainty, spirituality involves looking beyond one's own anxiety to a liminal space of not knowing everything [22]. Spirituality strengthens the ability to articulate uncertainty and in turn enables clarity that promotes an understanding of illness and change [22]. In this theme spirituality is seen as an essentially transcendent concept.

\section{Togetherness - Value Based Relationships}

In this theme, spirituality emerged as the need to be in the moment and involves the experience of interpersonal intimacy [25]. Tanyi et al. [23] pointed out that a solid relationship and connectedness are powerful spiritual interventions that contribute to individual spirituality. This includes embracing, crying together, gift giving, having coffee together and visiting each other [25]. Laughter, happy thoughts and the smiles of others were considered comforting. Being with others was described as a primary spiritual need and conversation was unnecessary. However, when talking with others a conversation about ordinary things was preferred [26]. Spirituality brought about the realization that the relationship with family and friends was important at the end of life [27] and involved finding a healthy balance in relationships between friends, family, society and God [28]. Furthermore, relationships also included disclosing and understanding fears and helplessness [27].

Of primary importance was the presence of others, community, nature and God [24]. Presence was the most influential element in enhancing the life-giving force of spirituality and positively influencing recovery [24]. The presence of family and friends was a calming experience that brought forth comfort and peace [24]. Presence was not only physical but a deep felt fellowship on a metaphysical or transcendent spiritual level, which brought forth a sense of peace, happiness, joy and hope [24]. In this type of presence, there is an intimate connection, a sense of awe, love and acceptance. Such presence can arise in any situation or context with a person, pet or in nature where there is a strong transcendental connection [28]. Finding balance involved introspection, reframing, adjusting, facing the challenge, prayer as well as choosing to avoid negative thoughts related to the body, mind and spirit [28]. This exemplifies spirituality in the religious and existential or universal sense.

\section{Developing Inner Strength}

Spirituality was associated with the development of inner strength, looking into one's own soul, the belief that there is more to life than the temporal as well as trying to understand who we are and why we are on this earth [29]. Spirituality begins with accountability for personal choices in all aspects of daily life and involves being responsible for taking good 
Table 1. Presentation of the studies included in the integrative review.

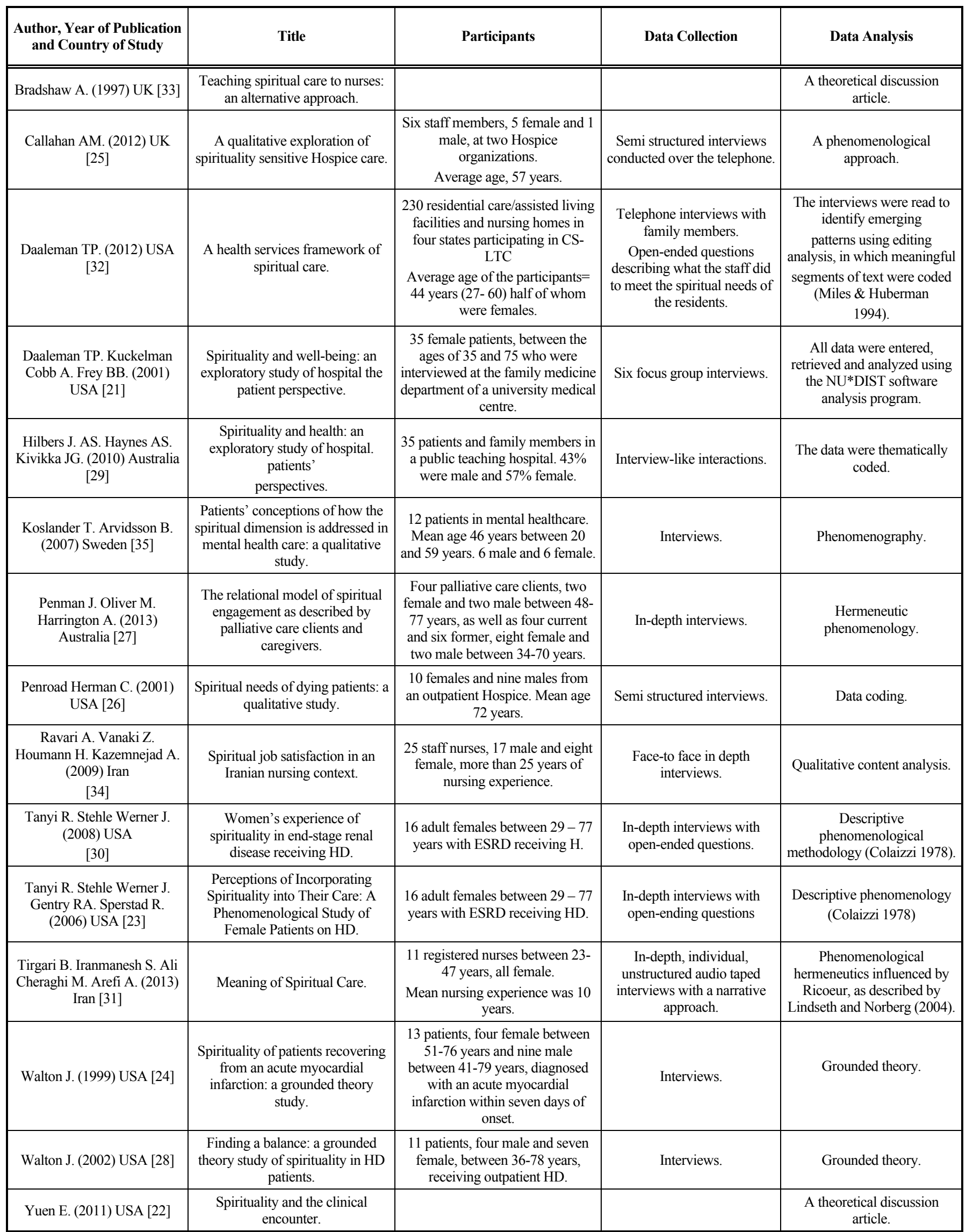


care of one's body, mind and spirit [28]. It does not only involve a relationship with others but also with oneself, something within a person, without which life would not be worth living [27]. Making sense of events within the life context comprised processing them in order to give them meaning, assessing and comprehending the impact of a perceived health condition on one's life. Finding meaning in life involved contextualizing health conditions by reflecting on the purpose of life or by outlining life goals and personal philosophies [21].

Finding the meaning of life was a dynamic, individual process that changed moment-to-moment and day-to-day events. It involved weighing the risk versus benefit, processes versus outcomes, good versus evil by means of introspection and reflection [28]. A sense of wellness in the face of illness contributed to normalcy, an ability to maintain one's dignity and a positive body image [24].

Spirituality as manifested in nature was expressed as the joy of seeing grass and trees and the desire to go for walks [26]. Those who were unable to walk wished to look at the trees surrounding the garden and to have flowers from the garden in their room. Patients reported the need to read inspirational texts several times each day or to sing and listen to music [26].

Several personality traits and attitudes were characterized as self-affirming: flexibility, hardiness, belief in self, determination and resiliency [21]. In other words, an inner spiritual struggle took place between one's weaknesses and the strength to make healthy choices by analyzing suitable options [28]. Spirituality was characterized as an inner force that provided insights into how to reduce anger, bitterness and fear in order to maintain a positive outlook [30]. According to Walton [23], spirituality creates inner strength and courage by providing the energy to face the next step in life, which leads to a sense of wellness and has a positive impact on health.

\section{Ministering to Patients}

A prerequisite for spirituality is a relationship characterized by mutuality, trust, ongoing dialogue and enduring presence. When ministering to patients, caregivers struggled to establish spirituality by creating a balance between the holistic and biomedical perspectives. When creating a balance, caregivers entered into a relationship that was reciprocal, close, mutual and preserved the patients' dignity, in which they were obliged to trust the patients as well as their feelings and ability [31]. Family members' view was that the provision of care went beyond medical treatment, encompassing emotional, social and spiritual needs [32]. 'Presencing' was the key to gaining access to the spiritual aspect of a clinical encounter [22]. It was the connection to the place of silence that enabled caregivers to acknowledge the hope and fear inherent in caring. Resting in a place free from fear facilitates genuine human connection, where presence with the patient can be felt and deepened [22]. Caregivers defined this genuine connection as a 'being with' relationship, which humanized patients and nurses, thereby allowing patients' spiritual concerns and spirituality to emerge [31]. Spirituality in caring was described as an invitation, encountering the patient as a unique person [31]. According to Tirgari et al. [31], the basic foundation of spirituality in caring is creating a relationship. Such spirituality assisted caregivers in maintaining a relationship based on trust, where the patients' dignity could be protected [31].
Caregivers should facilitate their patients' search for meaning by learning skills that enable them to express personal beliefs as well as by supporting patients to take part in relevant religious and cultural practices [33]. Furthermore, they should assess and meet their patients' spiritual needs by talking, questioning, listening and picking up clues [33]. Active listening requires nurses to be fully present, especially when patients appear depressed or upset [31]. Dialogue improved nurses' caring interactions, described as being with' [31] and willingness to answer questions [25]. Spirituality in caring therefore involves the ability to build confidence by listening to or just being with the patient [33]. In caring, confidence implies self-awareness, being non-judgemental and consistent as well as able to identify patient needs. This requires putting aside personal needs to avoid dominating the spirituality in the caring process [25]. It involves one human being responding to another with genuine understanding, openness and warmth [33] and encompasses patience, compassion, loyalty and honesty [23, 33].

Spiritual commitment develops into a meaningful notion and merges with sympathy, conscientious care, commitment and devotion [34]. Caregivers with this approach described caring as enjoyable and preferred it to the higher status of a more senior position [34]. Caregivers who took this perspective valued patient wellbeing more than their own, mainly because they regarded providing care as a form of worship. Such spiritual love and affection maintained an energetic approach to nursing [34].

When caregivers addressed the patients' spirituality they were assisted and strengthened in their struggle for better health [35]. A close relationship was important and touch was used to provide comfort in situations characterized by anxiety and physical pain [31].

\section{Maintaining One's Sense of Humanity}

The meaning of spirituality was described as caregivers encountering patients as cultural beings [31], which involved allowing them and their family members to express their feelings. Engaging in spiritual matters comprised beliefs and values that gave meaning and worth to existence [27]. 'Cocreating' was a mutual activity among patients, family members and caregivers that generated holistic caring with focus on maintaining the patients' humanity and dignity in the face of death [32]. According to Tanyi et al. [23], patients welcomed caregivers' conversations about ordinary things such as family, holidays and daily life events as well as the fact that they could trust both their professional competence and personal attributes [31]. Yuen [22] highlighted the inclusion of 'the unknown moment' in the clinical encounter as a key to acknowledging the spiritual aspect of the interaction, because spirituality is often a more personal search for transcendent understanding that does not encompass interpersonal activities [22].

\section{Viewing Life as a Gift Evokes a Desire to 'Give Back'}

According to Walton [28], a desire to help others in need is an important part of spirituality, which is also described as a life-giving force based on faith, discovering meaning and purpose in life and offering the gift of self to others [24]. 'Giving back' is a notion that emanates from introspection, reflection and the realization that medical treatment is a gift of 
life. Seeking balance in life involves everyday choices as well as setting goals and moving beyond personal requirements to those of others [28]. The need to contribute by helping to care for others is important, even in cases where the other is sick and close to death [26] as it is an expression of love, compassion and altruism [27]. Helping others also brings a sense of selfworth, personal fulfilment and satisfaction [28].

\section{Achieving Closure - Life Goes On}

Patients at the end of life described a need to view their life, which was subject to an ongoing revision process [21]. Reviewing life evoked happy thoughts and helped them to understand why things happened as they did, despite at times experiencing profound unhappiness [26]. It was important to undertake things one had wanted to do such as going on trips and carrying out tasks, for example making funeral arrangements in order to find peace before death. Although reviewing life was important, it was necessary to remain actively involved in decisions about the here and now, as well as informed, independent and able to maintain one's familiar lifestyle. Taking one day at a time represented an expression of spiritual value and had they not done so, they would have been unable to manage [26, 30].

Children were important at the end of life, as they were a reminder that life goes on and that another generation has hopes and dreams. Despite poor appetite it was important to join family members for meals [26].

Engaging in spiritual matters indicated personal transformation comprising a change of life direction and a new way of thinking. Spiritual engagement included prayer and was perceived as powerful, uplifting and helpful [27]. The spiritual dimension strengthened patients' ability to handle illness and also their will to live [22].

\section{DISCUSSION}

This integrative review attempts to describe experiences of the positive impact of spirituality and spiritual values in the context of nursing. It is difficult to draw any firm conclusions on the basis of the results, as spirituality comprises many perspectives at different levels of awareness [11]. However, the results revealed that spirituality was viewed as inclusive, fluid and personal. In the context of nursing, demands on caregivers are heavier when they have to provide insights into spiritual matters during encounters with patients. Therefore, each caregiver needs to consciously face her/his own spirituality in order to help patients achieve spiritual wellbeing. According to Carson [36], the development of spirituality is a dynamic process in which a person becomes aware of the meaning, aim and values of life, including all relationships.

From the caregivers' perspective, having a caring attitude implies being sensitive to the other, i.e., to the patient's needs [37], which also includes spirituality. It requires openness and sensitivity on the part of caregivers and becomes visible in virtue ethics $[37,38]$. This form of ethics develops from the carer-patient relationship for which the former's character is of the utmost importance. In virtue ethics, the human being is viewed as a whole, comprising body, mind and spirit. A finding in this integrative review was the spiritual value of 'being with', which is in line with Buber [20], who stated that an interpersonal relationship means offering to share one's life with the other. However, the authenticity of the human relationship is important, as in the absence of authenticity, there can be no humanity. 'Being with' in a caring context involves a meeting between two subjects, i.e., between an 'I' and a 'You' [20]. In such meetings spiritual values are fundamental, unlike encounters where the caregiver views the patient as an object, thus excluding spiritual values. The findings demonstrated that in an environment where spirituality can grow, the meeting between the caregiver and patient involved two subjects in a relationship of togetherness. Such an atmosphere meant that the caregiver became aware of her/his own spirituality and spiritual values, which were clarified.

Human beings try to alleviate their suffering in different ways [39]. In the present study, patients with various types of serious illness described how they attempted to alleviate their suffering by creating meaning, manifested as a new inner spiritual attitude that helped them to reconcile themselves with their changed life situation and prepared them to meet the fate that awaited them. Spiritual values in the creation of meaning included building a source of energy, development and hope linked to mutual giving and taking, helping and being helped. Having the energy and strength to struggle helped the suffering patient to maintain her/his dignity as a human being [39]. Transforming suffering into positive energy presupposes spirituality in caring, by having an opportunity to share one's story with another person.

Mounier [40] stated that there is no other spiritual force than that which flows from an inner richness, the condition of a person's inner development. It is the release of a spiritual force that pulls the person along in a movement out from the self. Mounier [40] stressed spiritual equality, which means the natural right to fulfilment within a communion of one's own choice. Our study revealed that the spiritual factor makes the human being universal and enables her/him to manifest her/himself in human love, which encompasses kindness, interest, responsiveness, understanding and the joy of meeting other people.

\section{LIMITATIONS OF THE REVIEW}

This integrative literature review provides an overview of some of the knowledge in the field of spirituality and spiritual values in the context of nursing, although it is possible that some relevant studies may not have been included given the limitations of this review [17]. Another weakness is the different meaning of the concepts of spirituality and spiritual values used in the analyzed articles, which contain no definition of the terms. Clarification of these concepts and values was therefore challenging, which should be kept in mind when criticizing this review. Because of the limitations and inconsistencies in the findings, additional research is needed to clarify the meaning and definition of spirituality and spiritual values in the context of nursing.

\section{CONCLUSION AND IMPLICATIONS FOR NURSING AND HEALTH POLICY}

The concepts of spirituality and caring were perceived as having the same meaning and no difference between them was reported. However, it was obvious that spirituality and spiritual values in the context of nursing are closely intertwined with the 
concept of caring. A caring attitude, spirituality and spiritual values belong together and should be the guiding inspiration for all nurses. It is the responsibility of nursing leadership and the organization to ensure that this is achieved.

\section{AUTHOR CONTRIBUTION}

GR is the main author and responsible for the study conception as well as the design of the introduction and method sections. She collected and analyzed the data in addition to drafting the manuscript and carrying out critical revisions. IB collected and analyzed data, drafted the manuscript and made critical revisions. ABS contributed to the drafting of the manuscript and the final critical revision. All authors approved the final version of this manuscript.

\section{CONFLICT OF INTEREST}

The authors confirm that this article content has no conflict of interest.

\section{ACKNOWLEDGEMENTS}

We are grateful to University West for financial support as well as Gullvi Nilsson and Monique Federsel for scrutinizing the English language.

\section{REFERENCES}

[1] Frankl V. God and the unconscious. Psychotherapy and religion. Stockholm: Natur och Kultur 1987 (In Swedish).

[2] Barbosa da Silva A. The relation between psychology, religion and health. In: Schuff H, Salvelsen R, Hagelia H, Eds. Anchoring and renewal. Ansgarskolen. Kristiansand: Portal Forlag 2013; pp. 10132013 (In Norwegian).

[3] Greenstreet WM. Teaching spirituality in nursing: a literature review. Nurse Educ Today 1999; 19: 649-58.

[4] Hussey T. Nursing and spirituality. Nurs Philos 2009; 10: 71-80.

[5] Kevern P. Who can give 'spiritual care'? The management of spirituality sensitive interactions between nurses and patients. J Nurs Manag 2012; 20: 981-9.

[6] Timmins F. McSherry W. Spirituality: the Holy Grail of contemporary nursing practice. J Nurs Manag 2012; 20: 951-7.

[7] Swinton J, Pattison S. Moving beyond clarity: towards a thin, vague, and useful understanding of spirituality in nursing care. Nurs Philos 2010; $11: 226-37$

[8] Ross L. Spiritual care in nursing: an overview of the research to date. J Clin Nurs 2006; 15: 852-62.

[9] Dalby P. Is there a process of spiritual change or development associated with ageing? A critical review of research. Aging Ment Health 2006; 10: 4-12.

[10] Tanyi RA. Towards clarification of the meaning of spirituality. J Adv Nurs 2002; 39: 500-9.

[11] Stoll RI. The essence of spirituality. In: Carson VB Ed. Spiritual dimensions of nursing practice. Philadelphia: WB Saunders Co. 1989; pp. 4-23.

[12] Cobb M, Dowrick C, Lloyd-Williams M. What can we learn about the spiritual needs of palliative care patients from the research literature? J Pain Symptom Manage 2012; 43: 1105-19.
[13] Draper P. An integrative review of spiritual assessment: implications for nursing management. J Nurs Manag 2012; 20: 970-80.

[14] Biro AL. Creating conditions for good nursing by attending to the spiritual. J Nurs Manag 2012; 20: 1002-11.

[15] Mouch CA, Sonnega AJ. Spirituality and recovery from cardiac surgery. J Relig Health 2012; 51: 1042-60.

[16] Hodge DR, Horvath VE. Spiritual needs in health care settings: a qualitative meta-synthesis of clients' perspectives. Soc Work 2011; 56: 306-16.

[17] Whittemore R, Knafl K. The integrative review: updated methodology J Adv Nurs 2005; 52: 546-53.

[18] Friberg F, Granum V, Bergh A-L. Nurses' patient-education work: conditional factors - an integrative review. J Nurs Manag 2012; 20 : $170-6$.

[19] Kierkegaard S. Either - Or. Köpenhamn: Meyer 1943; (In Swedish).

[20] Buber M. The knowledge of man. Selected essays. Friedman M, Smith RG. Trans. Atlantic Highlands: Humanities Press International Inc. 1965/1988.

[21] Daaleman TP, Kuckelman Cobb A, Frey BB. Spirituality and wellbeing: an exploratory study of the patient perspective. Soc Sci Med 2001; 53: 1503-11.

[22] Yuen E. Spirituality and the clinical encounter. Int J Hum Car 2011; 15 42-6.

[23] Tanyi R, Werner SJ, Recine SA, Sperstad R. Perceptions of incorporating spirituality into their care. A phenomenological study of female patients on hemodialysis. Nephrol Nurs J 2006; 33: 532-8.

[24] Walton J. Spirituality of patients recovering from an acute myocardial infarction: a grounded theory study. J Holist Nurs 1999; 17: 34-72.

[25] Callahan AM. A qualitative exploration of spirituality sensitive Hospice care. J Soc Serv Res 2012; 38: 144-55.

[26] Herman PC. Spiritual needs of dying patients: a qualitative study. Oncol Nurs Forum 2001; 28: 67-72.

[27] Penman J, Oliver M, Harrington A. The relational model of spiritual engagement depicted by palliative care clients and caregivers. Int J Nurs Pract 2013; 19: 39-46.

[28] Walton J. Finding a balance: a grounded theory study of spirituality in hemodialysis patients. Nephrol Nurs J 2002; 29: 447-55.

[29] Hilbers J, Haynes AS, Kivikko JG. Spirituality and health: an exploratory study of hospital patients' perspectives. Aust Health Rev 2010; 34: 3-10.

[30] Tanyi RA, Stehle Werner J. Women's experience of spirituality within end-stage renal disease and hemodialysis. Clin Nurs Res 2008; 17: 3249.

[31] Tirgari B, Iranmanesh S, Cheraghi AM, Arefi A. Meaning of spiritual care. Holist Nurs Pract 2013; 27: 199-206.

[32] Daaleman T. A health services framework of spiritual care. J Nurs Manag 2012; 20: 1021-8.

[33] Bradshaw A. Teaching spiritual care to nurses: an alternative approach. Int J Palliat Nurs 1997; 3: 51-57.

[34] Ravari A, Vanaki Z, Houmann H, Kazemnejad A. Spiritual job satisfaction in an Iranian nursing context. Nurs Ethics 2009; 16: 19-30.

[35] Koslander T, Arvidsson B. Patients' conceptions of how the spiritual dimension is addressed in mental health care: a qualitative study. J Adv Nurs 2007; 57: 597-604.

[36] Carson VB. Spiritual development across the life span. In: Carson VB, Ed. Spiritual dimensions of nursing practice. Philadelphia: WB Saunders Co. 1989; pp. 24-51.

[37] Gilligan C. In a different voice: Psychological Theory and Women's Development. Cambridge: Harvard University Press 1993.

[38] Beauchamp TL, Childress JF. Principles of biomedical ethics. $6^{\text {th }}$ ed. New York: Oxford University Press 2013.

[39] Eriksson K. The suffering human being. Chicago: Nordic Studies Press 2006.

[40] Mounier E. Personalism. England: Routledge \& Kegan Paul Ltd. 1952. 